\title{
WEAR, MICROHARDNESS AND FRACTURE TOUGHNESS OF DIFFERENT CAD/CAM CERAMICS
}

\author{
Rasha Sayed Asaad* and Shereen Kotb Salem ${ }^{* *}$
}

\begin{abstract}
Objective: To evaluate wear of three CAD/CAM ceramics (Lithium disilicate, Zirconia reinforced-lithium silicate, Zirconia-based) and their opposing enamel antagonists in addition to their microhardness \& fracture toughness.

Materials and Methods: Thirty rectangular shaped samples (12 x $14 \times 2 \mathrm{~mm})$ were fabricated and divided into three groups according to the type of ceramic used (10 samples each): Group (IP): IPS e.max CAD, Group(VS):Vita Suprinity and Group(BZ): BruxZir. Each group was divided into two sub-groups (5 samples each) according to the testing procedure. The first subgroups were subjected to microhardness and fracture toughness tests, while the second sub-groups were first weighed then subjected to wear test and finally re-weighed again before being subjected to microhardness and fracture toughness tests.
\end{abstract}

Results: Wear results showed a significant difference in weight loss of tested ceramics and the antagonist tooth structure between (BZ) and both (IP) \& (VS) . Microhardness of the three ceramics were significantly different in each sub-group regardless of wear test. Regarding fracture toughness, there was a significant difference between (BZ) and both (IP) \& (VS) in both sub-groups. For all tested ceramics, both sub-groups (without wear and after wear) were not statistically significantly different regarding microhardness and fracture toughness.

Conclusions: BruxZir showed the best wear behavior and the worst abrasiveness to enamel. Microhardness and fracture toughness were the highest for zirconia-based ceramic but both parameters were not affected by thermo-mechanical aging of wear test for the three tested ceramics.

KEY WORDS: Wear, Microhardness, fracture toughness, CAD/CAM, Ceramics.

* Oral and Maxillofacial Prosthodontic Department, Faculty of Dentistry, King Abdulaziz University, Jeddah, Kingdom of Saudi Arabia.

** Associate Professor of Fixed Prosthodontics, Faculty of Dentistry, October 6 University, Giza, Egypt 


\section{INTRODUCTION}

$\mathrm{CAD} / \mathrm{CAM}$ is considered the most commonly used technology in dentistry being time saving, eliminating potential error sources and improving accuracy of indirect restorations ${ }^{(\mathbf{1}, 2)}$. Wide range of materials were developed based on this technology, one of the recent and most preferable by clinicians is the monolithic CAD/CAM blocks as it can overcome the chipping of low strength veneering layer of multilayered restorations ${ }^{(3)}$. Moreover, esthetic ceramic blocks are more wear resistant, biocompatible and color stable ${ }^{(4)}$.

Wear is described as a complex process that is affected by chemical, physical, and biological factors. On clinical basis, the direct contact between natural teeth and restorations, or between restorative materials could be the main cause of tooth or restorative material loss ${ }^{(5,6)}$. One of the main determinants for clinically successful restoration is the resistance of this restorative material and opposing teeth to wear. As exaggerated wear of natural teeth and restorations could result in unstable occlusion, reduction of occlusal vertical dimension, temporomandibular joint disfunction, fatigue of masticatory muscles, and poor esthetics due to impaired anterior guidance. So, the selection of restorative material that mimics the wear of natural enamel is crucial regarding previous invivo studies ${ }^{(7,8)}$. As monolithic ceramic prostheses are the most commonly used restorations lately, their wear and abrasiveness against natural teeth have become relevant factors in selecting an appropriate ceramic material ${ }^{(9)}$.

Surface hardness is a critical characteristic of an ideal restorative material in order to improve their clinical performance as it describes its abrasiveness to the opposing natural dentition. It is a surface property that measures material's resistance to permanent indentation, scratching or penetration. It is usually correlated to the material's mechanical strength ${ }^{(10)}$. It has been reported that any ceramic material with high hardness value can tolerate high masticatory forces ${ }^{(11)}$.
Ceramics are considered as brittle materials that are greatly sensitive to surface flaws and defects, which might occur due to thermal, chemical or mechanical factors that might cause localized stress concentration leading to propagation of induced cracks and finally resulting in occurrence of great failure. Material's fracture toughness is how it resists crack propagation ${ }^{(12)}$. It is closely linked to tensile stresses that should be attained in crack tip prior fracture is commenced. Also, it is one of important determinants for material's use intraorally, as materials with enhanced fracture toughness showed long term and better clinical serviceability ${ }^{(13)}$. Fracture toughness has been measured using different techniques; both, Precracked and V-Notch Single Edge beam techniques used flexural test in order to measure fracture toughness, while Indentation technique measures fracture toughness and Vickers hardness using length of indentation and cracks which occurred due to surface indentation by a Vickers diamond ${ }^{(\mathbf{1 4})}$.

Intraoral dental restorations suffer from aging which is a process enhanced by saliva, chemicals and mechanical stresses due to mastication. Therefore, invitro simulation of the oral environmental conditions is crucial for clinical relevance of scientific researches. Chewing simulator is a useful device for inspecting alterations in surface properties of dental materials during function in oral cavity. It should exert forces within the masticatory range in addition to the application of temperature fluctuations ${ }^{(15)}$. So, the microhardness and fracture toughness were evaluated and compared for all tested ceramic materials before and after thermo-mechanical aging.

Therefore, the current study aimed to evaluate wear of three different CAD/CAM ceramics and their abrasiveness to opposing enamel antagonists in addition to their microhardness \& fracture toughness. The current hypothesis is that no significant difference will be found between the three different materials as regards wear, microhardness and fracture toughness. 


\section{MATERIALS AND METHODS}

\section{Study Design}

Thirty rectangular shaped samples $(12 \times 14 \times 2$ $\mathrm{mm})$ were fabricated and divided into three groups according to the type of ceramic used (10 samples each): Group (IP): Lithium Disilicate (IPS e.max CAD, Ivoclar-Vivadent, Schaan, Liechtenstein), Group (VS): Zirconia reinforced-lithium silicate(Vita Suprinity, Vita Zahnfabrick, Bad Sackingen, Germany) and Group(BZ): Zirconia-based (BruxZir,Glidewell, Frankfurt, Germany). Then, each group was divided into two sub-groups (5 samples each) according to the testing procedure. The first sub-groups (without wear) were subjected to microhardness and fracture toughness tests, while the second sub-groups (after wear) were first weighed then subjected to wear test and finally reweighed again before being subjected to microhardness and fracture toughness tests.

\section{Samples preparation:}

CAD/CAM blocks of tested samples were sectioned with dimensions $(12 \times 14 \times 2 \mathrm{~mm})$ using a micro saw (Isomet 4000, Buehler, Illinois, USA). To ensure samples standardization, digital caliber (High-Accuracy Digimatic, Digital Micrometer, USA) was used to check the samples dimensions. Samples were ultrasonically cleaned in water bath for 10 minutes, air-dried and left for 24 hours to dry according to manufacturer recommendations.

Then, (IP) and (VS) samples were crystallized in (Programat P310, Ivoclar Vivadent) according to the manufacturers' instructions at $850^{\circ} \mathrm{C}$ and $840^{\circ} \mathrm{C}$, respectively. They were then finished using the finishing diamonds with $50 \mu \mathrm{m}$ and $25 \mu \mathrm{m}$ impregnated grit drills (Komet, Brassler, Germany) and finally samples were polished using Optra Fine polishing system (Ivoclar Vivadent AG, Schann, Liechtenstein). (BZ) samples were placed in a sintering furnace (Nabertherm, $\mathrm{GmbH}, \mathrm{Germany}$ ) at $1600^{\circ} \mathrm{C}$ as recommended by the manufacturer. Then they were polished using Diasynt Plus DIACERA Zirconia polishing system (EVE Dental, Germany).

\section{Testing Procedures}

\section{Wear test}

Samples of second sub-groups were weighed using high accurate four digital number scale with an accuracy of 0.0001 gm (Sartorius, Biopharmaceutical and laboratories, Germany).

Fifteen caries free premolars extracted for orthodontic reasons (patients' age range from 18 to 30 years old) were selected as antagonists. Teeth were washed and rubbed to remove blood, plaque, calculus and remnants of the periodontal ligament. Only teeth without enamel defects were chosen. They were stored in Hanks' balanced salt solution (HBSS) (American Bioinnovations, LLC, Sparks, USA). Then teeth were placed in plastic cylinders filled with acrylic resin $1 \mathrm{~mm}$ above the CEJ, then sectioned vertically under copious amount of water, using Isomet 1000 (Buehler, IL, USA). Sectioning was done in a mesio-distal direction separating the buccal cusps from the lingual ones followed by removal of lingual cusps. So, buccal cusps were used as antagonists to the ceramic samples in chewing simulator. These samples were weighed using a sensitive digital scale with accuracy of $0.0001 \mathrm{gm}$.

Wear test was conducted by thermo-mechanical aging of the samples utilizing chewing simulator (Robota- Ach-09075DC-T, AD-Tech Technology Co., Ltd., Germany). It has four chambers to perform vertical and horizontal movements. Each chamber has an upper Jackob's chuck for the tooth antagonist holder that is screw tightened while the ceramic samples embedded in lower plastic sample holder. Wear test parameters were: vertical movement 1 $\mathrm{mm}$, cycle frequency $1.6 \mathrm{~Hz}$., horizontal movement $3 \mathrm{~mm}, 5 \mathrm{~kg}$ weight was exerted. The tested samples were exposed to 37500 chewing cycles simulating 3 
months-service ${ }^{(16)}$. Simultaneous thermal aging was carried out by thermocycling in water bath at $5^{\circ} \mathrm{C}$ $155^{\circ} \mathrm{C}$ and dwell time 60 seconds. Then, ceramic samples and antagonists were re-weighed after the wear test.

\section{Microhardness Test}

Surface microhardness was measured in a digital microhardness tester (Model HVS-50, Laizhou Huayin Co., China). Vickers diamond indenter of the device performed three indentations on working surface of each sample with 200 grams load for 20 seconds to determine Vickers hardness number $(\mathrm{VHN})^{(\mathbf{1 7 )})}$ The average VHD was attained from the mean of three readings before and after aging.

\section{Microhardness was calculated from this formula ${ }^{(18)}$}

$$
\mathrm{HV}=1.854 \mathrm{P} / \mathrm{d}^{2}
$$

HV: Vickers hardness in $\mathrm{Kgf} / \mathrm{mm}^{2}$, P: load in Kgf and d: length of diagonals in $\mathrm{mm}$.

\section{Fracture Toughness Test}

Indentation technique was used to determine hardness and fracture toughness. On each sample 3 indentations were made at different locations then loaded with $19.6 \mathrm{~N}$ for 20 seconds in a microhardness tester. Cracks were formed around a Vickers diamond indenter and shown to emerge from the corners of the indentations. Cracks' size was determined by "c". Applied load was determined by comparing crack length from indent center to its half diagonal length. Figure 1

\section{Fracture toughness was obtained from this formula: ${ }^{(19)}$}

$$
\mathrm{K}_{\mathrm{IC}}=0.016(\mathrm{E} / \mathrm{H})^{0.5}\left(\mathrm{P} / \mathrm{c}^{1.5}\right)
$$

$\mathbf{K}_{\mathrm{IC}}$ : fracture toughness, (0.016): material-independent constant, E:elastic modulus specified according to Griggs et $\mathbf{a l}^{(20)}$. H:Vickers hardness, P: indenter load, and c: crack length (measured from indentation's center).

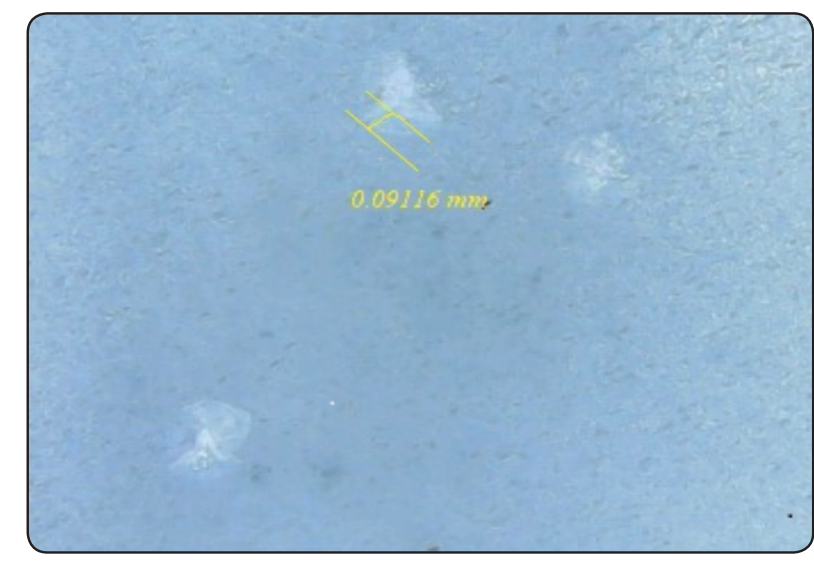

Fig.(1): Microscopic image of indentation crack showing crack extension

\section{Statistical Analysis}

Data were collected, tabulated and statistically analyzed using (IBM ${ }^{\circledR}$ SPSS ${ }^{\circledR}$ Statistics) version 20 and were shown as means and standard deviations. One-way ANOVA test followed by Tukey post hoc test was used to compare between the tested ceramics in non-related samples. Significance level was set at $\mathrm{P} \leq 0.05$.

\section{RESULTS}

Data were explored for normality using Kolmogorov-Smirnov and Shapiro-Wilk tests and showed parametric (normal) distribution.

\section{Wear Results (weight loss)}

Regarding the weight loss of tested ceramics. A significant difference was found between (BZ) and both (IP) \& (VS), while (IP) and (VS) showed insignificant difference. Where (IP) recorded the highest weight loss while (BZ) recorded the lowest weight loss. Table 1 and Figure 2

Concerning weight loss of tooth structure antagonist, (BZ) recorded the highest antagonist weight loss, while (IP) recorded the lowest antagonist weight loss. There was a significant difference between (BZ) and both (IP) \& (VS), while no significant difference was found between (IP) and (VS).

Table 1 and Figure 2 
TABLE (1): Means, standard deviations (SD) and statistical analysis results of wear(gm).

\begin{tabular}{|c|c|c|c|c|}
\hline \multirow{2}{*}{ Groups } & \multicolumn{4}{|c|}{ Wear } \\
\cline { 2 - 5 } & \multicolumn{2}{|c|}{ Ceramic material } & \multicolumn{2}{|c|}{ Antagonist } \\
\cline { 2 - 5 } & Mean & SD & Mean & SD \\
\hline IP & $0.0024^{\mathrm{b}}$ & 0.0003 & $0.0057^{\mathrm{b}}$ & 0.0002 \\
\hline VS & $0.0021^{\mathrm{b}}$ & 0.0003 & $0.0058^{\mathrm{b}}$ & 0.0002 \\
\hline BZ & $0.0011^{\mathrm{c}}$ & 0.0003 & $0.0097^{\mathrm{a}}$ & 0.0002 \\
\hline $\boldsymbol{p}$-value & \multicolumn{2}{|c|}{$\mathbf{0 . 0 0 4}^{*}$} & $<\mathbf{0 0 0 1}$ \\
\hline
\end{tabular}

Different letters are statistically significantly different.

*:Significant at $P \leq 0.05$.

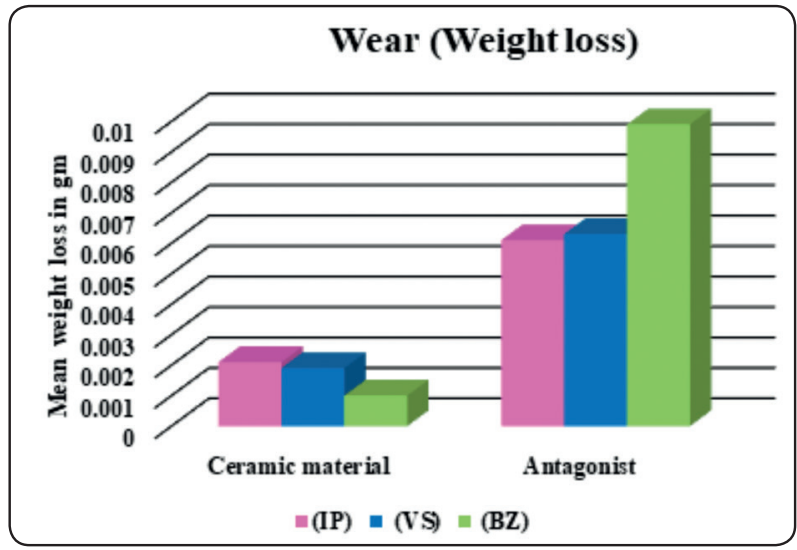

Fig. (2): Comparison between weight loss of the tested ceramics and the antagonist tooth

\section{Microhardness Results}

In each sub-group, there was a statistically significant difference between (BZ), (IP) and (VS). Where (BZ) recorded the highest mean values while (IP) recorded the least values. On the other hand, no statistically significant difference was found between both sub-groups. Table 2 and Figure 3
TABLE (2): Means, standard deviations (SD) and statistical analysis results of microhardness (VHN).

\begin{tabular}{|c|c|c|c|c|c|}
\hline \multirow{2}{*}{ Groups } & \multicolumn{5}{|c|}{ Microhardness } \\
\cline { 2 - 5 } & Without wear & \multicolumn{2}{|c|}{ After wear } & \multirow{2}{*}{ p-value } \\
\cline { 2 - 5 } & Mean & SD & Mean & SD & \\
\hline IP & $348.888^{\mathrm{c}}$ & 10.881 & $331.017^{\mathrm{c}}$ & 9.996 & 0.271 \\
\hline VS & $564.562^{\mathrm{b}}$ & 4.035 & $551.926^{\mathrm{b}}$ & 6.512 & 0.133 \\
\hline BZ & $740.061^{\mathrm{a}}$ & 8.656 & $714.505^{\mathrm{a}}$ & 9.581 & 0.132 \\
\hline p-value & $<\mathbf{0 . 0 0 1 *}$ & $<\mathbf{0 . 0 0 1 *}$ & \\
\hline
\end{tabular}

Different letters are statistically significantly different.

$*$ :Significant at $P \leq 0.05$.

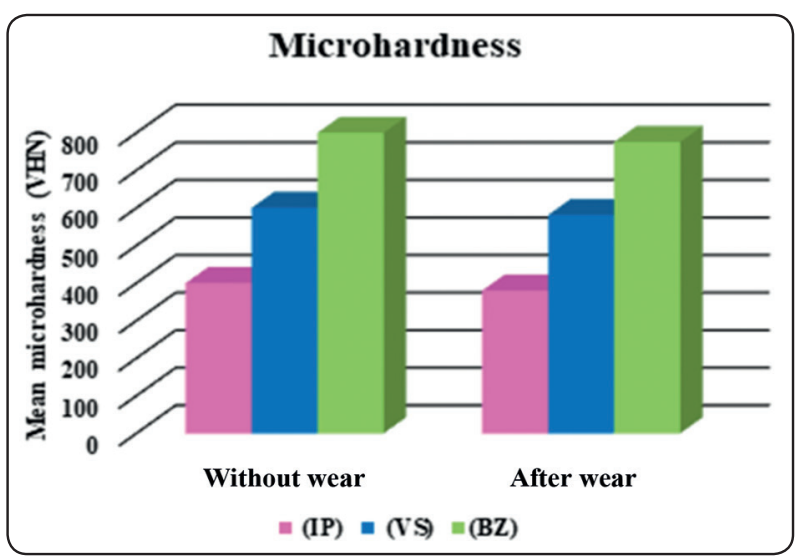

Fig. (3): Comparison between the microhardness of tested ceramics

\section{Fracture toughness Results}

In each sub-group, there was a statistically significant difference between (BZ) and both (IP) \& (VS), while between (IP) and (VS) no significant difference was found. Where (BZ) recorded the highest mean values while (IP) recorded the least values. On the other hand, no statistically significant difference was found between both sub-groups.

Table 3 and Figure 4 
TABLE (3): Means, standard deviations (SD) and statistical analysis results of fracture toughness (MPa.m ${ }^{0.5}$ )

\begin{tabular}{|c|c|c|c|c|c|}
\hline \multirow{3}{*}{ Groups } & \multicolumn{5}{|c|}{ Fracture toughness } \\
\hline & \multicolumn{2}{|c|}{ Without wear } & \multicolumn{2}{|c|}{ After wear } & \multirow{2}{*}{ p-value } \\
\hline & Mean & SD & Mean & SD & \\
\hline IP & $2.509^{b}$ & 0.223 & $2.128^{\mathrm{b}}$ & 0.063 & 0.146 \\
\hline VS & $2.849^{\mathrm{b}}$ & 0.080 & $2.708^{b}$ & 0.091 & 0.089 \\
\hline BZ & $5.191^{\mathrm{a}}$ & 0.493 & $5.418^{\mathrm{a}}$ & 0.591 & 0.592 \\
\hline p-value & \multicolumn{2}{|c|}{$<0.001 *$} & \multicolumn{2}{|c|}{$<0.001 *$} & \\
\hline
\end{tabular}

Different letters are statistically significantly different. *: Significant at $P \leq 0.05$.

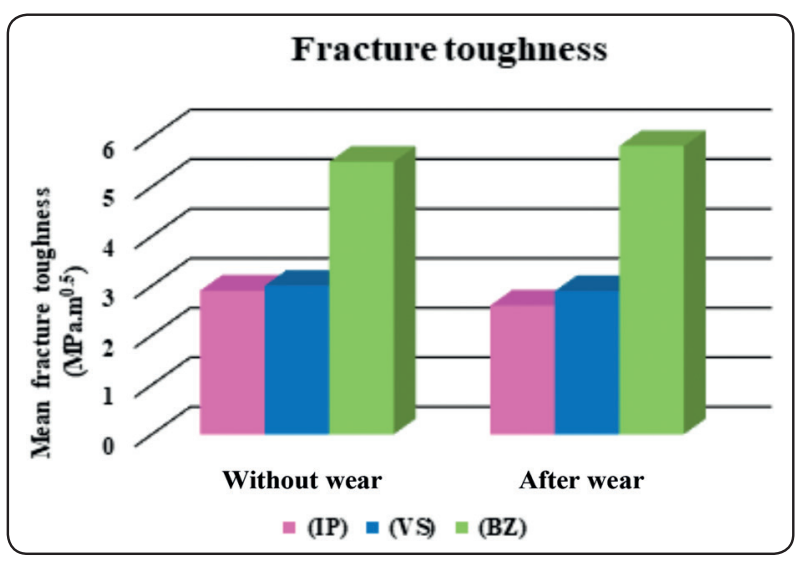

Fig. (4): Comparison between the fracture toughness of tested ceramics

\section{DISCUSSION}

This study investigated the behaviour of three CAD/CAM ceramics with different chemical compositions: (IP), (VS) and (BZ) regarding hardness, fracture toughness in addition to their own wear resistance and abrasiveness to opposing enamel. Industrially produced blocks had the privilege of eliminating laboratory construction errors due to human variability.
Wear of tooth structure as well as dental restorations is a prime factor that should be properly considered during selection of restorative materials. It was proposed that any restoration should have a wear rate that mimics enamel ${ }^{(21)}$. Using extracted human teeth as antagonists for evaluation of wear and abrasiveness of restorative materials gives more reliable data for a proper clinical guidance ${ }^{(22-24)}$. As researches that studied materials' wear against any other material disregarded their abrasiveness to human enamel and the fact is that enamel roughens due to wear affecting its own wear behaviour as well as abrasiveness to opposing materials. Teeth were stored in HBBS to prevent enamel dehydration and maintain enamel hardness till use ${ }^{(25,26)}$. Teeth sectioning was done under excessive amount of water to decrease the effect of generated heat. Chewing simulator load was $5 \mathrm{Kg}$ that is corresponding to $49 \mathrm{~N}$ representing physiological occlusal forces in patients with normal occlusion ${ }^{(5,7,27)}$. Surface treatment of all ceramic prostheses might affect the rate of enamel wear as it was proved that the unglazed and unpolished ceramic surfaces were accompanied by higher rate of enamel wear than glazed or polished surfaces ${ }^{(28,29)}$. In this study, polishing was selected as some investigators found that glazed ceramic surfaces resulted in more natural teeth wear compared to polished surfaces ${ }^{(30-32)}$.

Hardness is an essential property to compare restorative materials' resistance to surface indentation through a combined effect of brittle fracture as well as plastic flow. It marks out materials' wear resistance as well as their abrasiveness to the opposing. It directly affects materials' ability for finishing and polishing ${ }^{(33,34)}$. A pyramidal diamond indenter was compressed into a polished surface under known load and conditions to measure microhardness to correlate indentation size to the materials' hardness.

Yilmaz et al (2007) $)^{(12)}$, reported laboratory limitations encountered in strength testing for prediction of brittle materials' structural performance, so 
that mechanical properties might not give enough data to accurately estimate clinical success, performance \& longevity of all-ceramic materials yet, it is proved that materials with enhanced fracture toughness would behave clinically in a better way ${ }^{(35)}$. Fracture toughness is considered a suitable measure of brittle materials' intrinsic resistance to crack propagation as well as their ability to absorb strain-energy resulting from applied force ${ }^{(12,36,37)}$. In this study,the indentation technique was chosen for assessing fracture toughness of the three tested ceramics as it is a simple and reliable method that requires samples with small dimensions; the accompanied crack growth is analogous to cracks that commonly occur clinically ${ }^{(33,38)}$.

Microhardness results revealed no significant difference within groups due to aging procedures however, the significant difference found between the three tested ceramics in both subgroups(without wear and after wear)might be related to their different microstructures as it was reported that many factors should be considered for better interpretation of ceramics' hardness data like crystalline phase, grain sizes, grain boundaries effect and surface porosities ${ }^{(39,40)}$. The chemical composition of (IP), (VS) and (BZ) groups are lithium disilicate ceramic, zirconia reinforced-lithium silicate ceramic and polycrystalline zirconia-based ceramic, respectively. Additionally, the lower hardness of both (IP) and (VS) in relation to (BZ) ceramic might be explained according to $\mathbf{L i} \mathbf{D}$ et al (2016) $^{(41)}$, who concluded that increasing residual tensile stresses within glassy matrix reduced the resistance to deformation of glass-ceramics, and subsequently decreased their hardness.

The current study results came in partial agreement with Vasiliu et al (2020) ${ }^{(42)}$, who recorded no significant effect of thermocycling on microhardness of lithium disilicate and zirconia reinforcedlithium silicate ceramics, while they found no significant difference in microhardness of both ceramics.
They related this to the regular scattering crystals within ceramic structure of both materials ${ }^{(43)}$. However, this controversy might be related to that they exposed the samples to 10000 thermocycles only while this study samples were subjected to 37500 thermo-mechanical cycles which might have contributed in more material deterioration. Also, hardness value of any material is a function of test type and loading conditions ${ }^{(40)}$.

Fracture toughness of the tested ceramics was not significantly affected by thermo-mechanical aging of wear test, but (BZ) showed statistically significantly higher fracture toughness than the other two ceramics. This comes in accordance with Sonmez et al (2018) $)^{(44)}$, who didn't find a significant effect of thermocycling on hardness and fracture toughness of IPS e.max CAD, as SEM images showed no gross changes due to thermocycling,also XRD analysis showed regular distribution of disilicate crystals within the matrix. Moreover, Harada K et al(2016) ${ }^{(\mathbf{1 4})}$, found that zirconia-based ceramics' hardness and fracture toughness were not affected by aging. Cook and Pharr (1990) ${ }^{(45)}$ and Kruzica et al(2009) $)^{(46)}$, reported that indentation cracking details are material dependent, as most of brittle materials acquire subcritical crack growth due to indentation, resulting in extension of cracks that might proceed toward threshold of subcritical crack growth. Cracks extension is affected by time elapsed between indentation and measurement as well as the testing environment. In this study, (BZ) recorded the highest fracture toughness among the tested ceramics that might be due to the strengthening mechanism known as transformation toughening which is a unique property of zirconia ceramics. As in specific conditions, like crack initiation,zirconia ceramic molecular configuration undergoes phase transformation, resulting in volumetric changes that give rise to compressive stress, which counteract the crack propagation leading to an increase in its fracture toughness and strength $^{(47)}$. The (BZ) fracture toughness results 
were coinciding with Guazzato et al. (2004) $)^{(48,49)}$ and Yilmaz et al (2007) ${ }^{(\mathbf{1 2})}$, who studied fracture toughness of different ceramics and reported that zirconia based ceramic materials had significantly the highest fracture toughness values and was much stronger relative to other ceramic materials. They related these results to the increased amount of crystals in fully sintered $\mathrm{ZrO}_{2}$ ceramic resulting in improved physical properties which might have a favorable effect on clinical performance of zirconia restorations ${ }^{(\mathbf{1 2})}$.

Regarding wear results, both (IP) and (VS) showed significantly higher weight loss with significantly lower weight loss of the opposing enamel in comparison to (BZ) and their opposing after thermo-mechanical aging which comes in accordance with many researchers, who found that zirconia showed less wear than lithium disilicate ceramics when opposed to enamel ${ }^{(50-52)}$. This was also in agreement with Ludovichetti et al (2018) $^{(53)}$, who reported that zirconia-based ceramics caused higher enamel wear than (IP)and (VS) and attributed this to higher hardness of zirconia than the other ceramic materials. These wear results were not in accordance with Mormann et al $(\mathbf{2 0 1 3})^{(\boldsymbol{( )}}$, who found that zirconia, despite of its high hardness value, showed the lowest enamel wear rate than both (IP) and (VS). This contradiction in results might be due to variations in manufacturing process and the use of different brands of zirconia. Also, it was reported that recognizing the microstructure of materials could be beneficial in predicting their wear rate ${ }^{(21)}$.

Wear results in this study, followed the pattern that as the material's microhardness increased, material's wear decreased \& its abrasiveness to opposing enamel increased. But for (IP) and (VS), although they had significantly different microhardness results, yet they showed insignificant difference in their wear and opposing teeth. Despite that many scientific researches related dental materials' hardness to their wear resistance and abrasiveness to the opposing, but recently ceramic materials' wear behavior is described as complex multifactorial, influenced by many variables, hardness is one of them but not the only significant variable. These variables include microstructure, porosity, crystal size, surface roughness, and environment ${ }^{(28,54-58)}$. Presence of an exact and precise correlation between hardness and wear of brittle materials was described by being inappropriate, as they wear through subsurface microfractures, not like metals that wear by plastic deformation ${ }^{(52,59,60)}$. These results might be attributed to that zirconia is less prone to surface microfracture ${ }^{(61)}$, while wear of lithium disilicate and zirconia reinforced-lithium silicate ceramics results in protrusion of the larger size crystals from restoration surface, and that these crystals are likely to be rubbed off by frictional forces ${ }^{(62)}$. So, more enamel wear was likely to result from zirconia, as it has strong surface hardness ${ }^{(63,64)}$. IPS e.max CAD contains dense crystalline microstructure with crystal size up to $2-3 \mu \mathrm{m}$, while Vita Suprinity is characterized by its homogeneous, fine crystalline microstructure of $0.5 \mu \mathrm{m}$, the smaller particle size for the same surface area might increase number of pores. This might explain the insignificant difference between wear of (IP) and (VS) and also why (BZ) showed the highest hardness and wear resistance followed by(VS) then (IP).During wear process, ceramic subsurface porosities might be exposed, creating defects with sharp edges resulting in increased wear of the opposing ${ }^{(65-67)}$. Although some researches mentioned that a direct correlation between wear and hardness cannot always be recognised, due to the multifactorial nature of the wear process ${ }^{(33,68,69)}$, yet, Brusilová et al (2017) ${ }^{(\mathbf{7 0 )}}$, demonstrated a direct relationship between ceramics' wear and fracture toughness/hardness ratio. Ceramic fracture toughness/ hardness ratio was found to be of most significance in determining the wear behavior of ceramics. Wear was greatly affected by hardness of the tested ceramic materials, where the material with the highest hardness showed the highest wear resistance. 
Therefore, the hypothesis is partially accepted as there was a significant difference between the three tested ceramics regarding microhardness, while there was no significant difference in wear and fracture toughness results between lithium disilicate and zirconia reinforced-lithium silicate ceramics.

\section{CONCLUSIONS}

Within the limitations of this study it was concluded that

1. BruxZir showed the best wear behavior and the worst abrasiveness to enamel.

2. Microhardness and fracture toughness were the highest for zirconia-based ceramic but both parameters were not affected by thermo-mechanical aging of wear test for the three tested ceramics.

\section{REFERENCES}

1. Ruse ND and Sadoun MJ. Resin-composite blocks for dental CAD/CAM applications. J Dent Res.2014; 93(12):1232-34.

2. Baroudi K and Ibraheem SN. Assessment of Chair-side Computer-Aided Design and Computer-Aided Manufacturing Restorations: A Review of the Literature. J Int Oral Health. 2015;7(4): 96-104.

3. Silva LH, Lima E, Miranda RBP, Favero SS, Lohbauer U, Cesar PF. Dental ceramics: a review of new materials and processing methods. Braz. Oral Res. 2017;31(1): e58.

4. Tekçe N, Fidan S, Tuncer S, Kara D, Demirci M. The effect of glazing and aging on the surface properties of CAD/ CAM resin blocks, J Adv.Prosthodont.2018;10(1):50-7.

5. D'Arcangelo C, Vanini L, Rondoni GD, De Angels F. Wear properties of dental ceramics and porcelains compared with human enamel. J Prosthet. Dent. 2016; 115:350-55.

6. Mörmann WH, Stawarczyk B, Ender A, Sener B, Attin T, Mehl A. Wear characteristics of current aesthetic dental restorative CAD/CAM materials: Two-body wear, gloss retention, roughness and Martens hardness. J Mech Behav. Biomed. Mater. 2013; 20:113-25.

7. Jung YS, Lee JW, Choi YJ, Ahn JS, Shin SW, Huh JB. A study on the in vitro wear of the natural tooth structure by opposing zirconia or dental porcelain. J Adv. Prosthodont. 2010; 2:111-15.
8. D’Arcangelo C., Vanini L., Rondoni G.D., Pirani M., Vadini M., Gattone M., De Angelis F. Wear properties of a novel resin composite compared to human enamel and other restorative materials. Oper. Dent. 2014; 39:612-18.

9. Gwon B, Bae EB, Lee JJ, Cho WT, Bae HY, Choi JW, Huh JB. Wear characteristics of dental ceramic CAD/CAM materials opposing various dental composite resins. Materials. 2019; 12(11): 1839 .

10. Koizumi H, Saiki O, Nogawa H, Hiraba H, Okazaki T, Matsumura H. Surface roughness and gloss of current $\mathrm{CAD} / \mathrm{CAM}$ resin composites before and after toothbrush abrasion. Dent Mater J. 2015;34(6): 881-7.

11. Elsaka SE, Elnaghy AM. Mechanical properties of zirconia reinforced lithium silicate glass-ceramic. Dent Mater. 2016;32(7): 908-14.

12. Yilmaz H, Aydin C, Gul BE: Flexural strength and fracture toughness of dental core ceramics. J Prosthet Dent 2007; 98:120-28.

13. Albakry M, Guazzato M, Swain MV. Fracture toughness and hardness evaluation of three pressable all-ceramic dental materials. J Dent. 2003; 31:181-88.

14. Harada K, Shinya A, Gomi H, Hatano Y, Shinya A, Raigrodski AJ. Effect of accelerated aging on the fracture toughness of zirconias J Prosthet Dent.2016;115(2):215-23.

15. Alshali RZ, Salim NA, Satterthwaite JD, Silikas N. Longterm sorption and solubility of bulk-fill and conventional resin-composites in water and artificial saliva. J Dent. 2015;43(12):1511-18.

16. Nawafleh N, Hatamleh M, Elshiyab S, Mack F. Lithium disilicate restorations fatigue testing parameters: A Systematic Review. J Prosthodont. 2016; 25:116-26.

17. Şen N, Tuncelli B, Göller G. Surface deterioration of monolithic CAD/CAM restorative materials after artificial abrasive toothbrushing. J Adv Prosthodont. 2018;10(4):271.

18. Srikanth P. Developing correlations among the different hardness numbers for aluminum. South asian j. eng. tech. 2015;2(1):66-72.

19. Scherrer SS, Denry IL, Anselm Wiskott HW, Belser UC. Effect of water exposure on the fracture toughness and flexure strength of a dental glass. Dent Mater. 2001;17(4):367-71.

20. Griggs JA, Kishen A, Le KN. Mechanism of strength increase for a hydrothermal porcelain. Dent Mater. 2003;19(7):625-31. 
21. Seghi RR, Rosenstiel SF, Bauer P. Abrasion of human enamel by different dental ceramics in vitro. J Dent Res. 1991; 70:221-5.

22. Kohyama K, Hatakeyama E, Sasaki T, Dan H, Azuma T, Karita K. Effects of sample hardness on human chewing force: a model study using silicone rubber. Arch Oral Biol. 2004; 49: 805-16.

23. Preis V, Behr M, Handel G, Schneider-Feyrer S, Hahnel S, Rosentritt M. Wear performance of dental ceramics after grinding and polishing treatments. J Mech Behav Biomed Mater. 2012; 10:13-22.

24. Wang L, Liu Y, Si W, Feng H, Tao Y, Ma Z. Friction and wear behaviors of dental ceramics against natural tooth enamel. J Eur Ceram Soc. 2012; 32(11): 2599-606.

25. Sajewicz E. On evaluation of wear resistance of tooth enamel and dental materials. Wear. 2006; 260(11):1256-61.

26. Habelitz S, Marshall Jr GW, Balooch M, Marshall SJ. Nanoindentation and storage of teeth. J Biomech.2002; 35(7), 995-8.

27. Gibbs $\mathrm{CH}$, Mahan PE, Lundeen HC, Brehnan K, Walsh EK, Holbrook WB. Occlusal forces during chewing and swallowing as measured by sound transmission. J Prosthet. Dent. 1981; 46(4), 443-9.

28. Magne P, Oh WS, Pintado MR, DeLong R. Wear of enamel and veneering ceramics after laboratory and chairside finishing procedures. J Prosthet Dent 1999; 82(6): 669-79.

29. al-Hiyasat AS, Saunders WP, Sharkey SW, Smith GM, Gilmour WH. The abrasive effect of glazed, unglazed, and polished porcelain on the wear of human enamel, and the influence of carbonated soft drinks on the rate of wear. Int J Prosthodont 1997; 10(3): 269-82.

30. Palmer DS, Barco MT, Pelleu GB Jr, McKinney JE. Wear of human enamel against a commercial castable ceramic restorative material. J Prosthet Dent 1991; 65(2): 192-5.

31. Jacobi R, Shillingburg HT Jr, Duncanson MG Jr. A comparison of the abrasiveness of six ceramic surfaces and gold. J Prosthet Dent 1991; 66(3): 303-9.

32. Jagger DC, Harrison A. An in vitro investigation into the wear effects of unglazed, glazed, and polished porcelain on human enamel. J Prosthet Dent 1994; 72(3): 320-3.

33. Seghi RR, Denry IL, Rosenstiel SF. Relative fracture toughness and hardness of new dental ceramics. J Prosthet Dent.1995;74(2):145-50.
34. Vásquez V, Ozcan M, Nishioka R, Souza R, Mesquita A, Pavanelli C. Mechanical and thermal cycling effects on the flexural strength of glass ceramics fused to titanium. Dent Mater J. 2008; 27(1), 7-15.

35. Fischer H, Marx R. Fracture toughness of dental ceramics: comparison of bending and indentation method. Dent Mater. 2002; 18(1):12-9.

36. Kelly JR: Perspectives on strength. Dent Mater. 1995; 11(2):103-10.

37. Mecholsky Jr JJ: Fracture mechanics principles. Dent Mater. $1995 ; 11: 111-2$

38. VITA Zahnfabrik. Vita Suprinity Technical and scientific documentation. 2014. Available from: https://www.vitazahnfabrik. com.

39. Egilmez F, Ergun G, Cekic-Nagas I, Vallittu PK, Lassila LVJ. Does artificial aging affect the mechanical properties of CAD/CAM composite materials? J. Prosthodont Res. 2018, 62(1), 65-74.

40. Sargent PM, Page TF. The influence of microstructure on the microhardness of ceramic materials. Proc Brit Ceram. Soc.1978; 26: 209-24.

41. Li D, Guo JW, Wang XS, Zhang SF, He L. Effects of crystal size on the mechanical properties of a lithium disilicate glass-ceramic. Mater. Sci. Eng. A. 2016; 669:332-39.

42. Vasiliu RD, Porojan SD, Bîrdeanu MI, Uțu ID, Porojan L. The effect of thermocycling and surface treatments on the surface roughness and microhardness of three heat-pressed ceramics systems. Crystals. 2020, 10(3):160.

43. McCabe JF, Carrick TE. A statistical approach to the mechanical testing of dental materials. Dent Mater. 1986, 2(4), 139-42.

44. Sonmez N, Gultekin P, Turp V, Akgungor G, Sen D, Mijiritsky E. Evaluation of five CAD/CAM materials by microstructural characterization and mechanical tests: a comparative in vitro study. BMC Oral Health.2018; 18(1):5.

45. Cook RF, Pharr GM. Direct observation and analysis of indentation cracking in glasses and ceramics. J Am Ceram Soc. 1990; 73 (4): 787-817.

46. Kruzica JJ, Kim DK, Koesterc KJ, Ritchiec RO. Indentation techniques for evaluating the fracture toughness of biomaterials and hard tissues. J Mech Behav Biomed Mater. 2009; 2(4): 384-95.

47. Marinis, Aristotelis. Fracture toughness of yttrium stabilized zirconia sintered in conventional and microwave ovens. MS (Master of Science) thesis, University of Iowa, 2011. 
48. Guazzato M, Albakry M, Ringer SP, Swain MV. Strength, fracture toughness and microstructure of a selection of all-ceramic materials. Part I. Pressable and alumina glassinfiltrated ceramics. Dent Mater. 2004; 20(5):441-8.

49. Guazzato M, Albakry M, Ringer SP, Swain MV. Strength, fracture toughness and microstructure of a selection of allceramic materials. Part II. Zirconia-based dental ceramics. Dent Mater. 2004 ;20(5):449-56.

50. Heintze SD, Cavalleri A, Forjanic M, Zellweger G, Rousson V. Wear of ceramic and antagonist-a systematic evaluation of influencing factors in vitro. Dent Mater. 2008; 24(4), 433-49.

51. Nakashima J, Taira Y, Sawase T. In vitro wear of four ceramic materials and human enamel on enamel antagonist. Eur J Oral Sci. 2016; 124(3): 295-300.

52. D'Arcangelo C, Vanini L, Rondoni GD, Vadini M, De Angelis F. Wear evaluation of prosthetic materials opposing themselves. Oper Dent. 2018; 43(1): 38-50.

53. Ludovichetti FS, Trindade FZ, Werner A, Kleverlaan CJ, Fonseca RG. Wear resistance and abrasiveness of CADCAM monolithic materials. J Prosthet Dent.2018; 120(2): 318.e1-e8.

54. Faria ACL, de Oliveira AA, Alves Gomes E, Silveira Rodrigues RC, Faria Ribeiro R. Wear resistance of a pressable low-fusing ceramic opposed by dental alloys. J Mech Behav Biomed Mater. 2014; 32:46-51.

55. Hudson JD, Goldstein GR, Georgescu M. Enamel wear caused by three different restorative materials. J Prosthet Dent 1995; 74(6): 647-54.

56. al-Hiyasat AS, Saunders WP, Sharkey SW, Smith GM, Gilmour WH. Investigation of human enamel wear against four dental ceramics and gold. J Dent 1998; 26(5-6): 487-95.

57. Fisher RM, Moore BK, Swartz ML, Dykema RW. The effects of enamel wear on the metal- porcelain interface. $J$ Prosthet Dent 1983; 50(5): 627-31.

58. Clelland NL, Agarwala V, Knobloch LA, Seghi RR. Wear of enamel opposing low-fusing and conventional ceramic restorative materials. J Prosthodont 2001; 10(1):8-15.
59. Oh WS, Delong R, Anusavice KJ. Factors affecting enamel and ceramic wear: a literature review. J Prosthet Dent 2002; 87(4):451-9.

60. Sripetchdanond J, Leevailoj C. Wear of human enamel opposing monolithic zirconia, glass ceramic, and composite resin: An in vitro study. J Prosthet Dent. 2014; 112(5):1141-50.

61. Lawson NC, Bansal R, Burgess JO. Wear, strength, modulus and hardness of CAD/CAM restorative materials. Dent Mater. 2016; 32(11): e275-e83.

62. Sumino N, Tsubota K, Takamizawa T, Shiratsuchi K, Miyazaki M, Latta MA. Comparison of the wear and flexural characteristics of flowable resin composites for posterior lesions. Acta Odontol Scand. 2013; 71(3-4), 820-7.

63. Sundh A, Sjogren G. Fracture resistance of all-ceramic zirconia bridges with differing phase stabilizers and quality of sintering. Dent Mater 2006; 22(8): 778-84.

64. Aboushelib MN, de Jager N, Kleverlaan CJ, Feilzer AJ. Effect of loading method on the fracture mechanics of two layered all-ceramic restorative systems. Dent Mater. 2007; 23(8): 952-9.

65. Delong R, Pintado MR, Douglas WH. The wear of enamel opposing shaded ceramic restorative materials: an in vitro study. J Prosthet Dent. 1992; 68(1): 42-8.

66. DeLong R, Douglas WH, Sakaguchi RL, Pintado MR. The wear of dental porcelain in an artificial mouth. Dent Mater. 1986; 2(5): 214-9.

67. KellyJR, Campbell SD, Bowen HK. Fracture-surface analysis of dental ceramics. J Prosthet Dent 1989; 62(5): 536-41.

68. Mair LH, Stolarski TA, Vowles RW, Lloyd CH. Wear: mechanisms, manifestations and measurement. Report of a workshop. J Dent. 1996;24(1-2):141-8.

69. Zang Yi, Xu D, Rao P, Lu M, Wu J. Friction behavior of dental porcelain with different leucite particle sizes. J Am Ceram Soc. 2008;91(5):1678-81.

70. Brusilová A, Švec P, Gábrišová1 Z, Pokusová M. The effects of mechanical properties and sintering duration on the wear behaviour of silicon nitride. Mater Sci Eng.174 (2017) 012007. 